Article

\title{
The Lack of the Association of the CCR5 Genotype with the Clinical Presentation and Frequency of Tick-Borne Encephalitis in the Polish Population
}

\author{
Sambor Grygorczuk ${ }^{1, *}$, Justyna Dunaj-Małyszko ${ }^{1}$, Artur Sulik ${ }^{2}$ (D), Kacper Toczyłowski ${ }^{2}$, Piotr Czupryna ${ }^{1}$, \\ Agnieszka Żebrowska ${ }^{3}$ and Miłosz Parczewski ${ }^{4}$ (i)
}

Citation: Grygorczuk, S.; Dunaj-Małyszko, J.; Sulik, A.;

Toczyłowski, K.; Czupryna, P.;

Żebrowska, A.; Parczewski, M. The Lack of the Association of the CCR5 Genotype with the Clinical Presentation and Frequency of

Tick-Borne Encephalitis in the Polish Population. Pathogens 2022, 11, 318. https://doi.org/10.3390/pathogens 11030318

Academic Editor: José A. Oteo

Received: 1 February 2022

Accepted: 1 March 2022

Published: 4 March 2022

Publisher's Note: MDPI stays neutral with regard to jurisdictional claims in published maps and institutional affiliations.

Copyright: (C) 2022 by the authors. Licensee MDPI, Basel, Switzerland. This article is an open access article distributed under the terms and conditions of the Creative Commons Attribution (CC BY) license (https:// creativecommons.org/licenses/by/ $4.0 /)$
1 Department of the Infectious Diseases and Neuroinfections, Faculty of Medicine, Medical University of Białystok, ul. Żurawia 14, 15-540 Białystok, Poland; justyna.dunaj@umb.edu.pl (J.D.-M.); piotr.czupryna@umb.edu.pl (P.C.)

2 Department of the Pediatric Infectious Diseases, Faculty of Medicine, Medical University of Białystok, ul. Jerzego Waszyngtona 17, 15-274 Białystok, Poland; artur.sulik@umb.edu.pl (A.S.); kacper.toczylowski@umb.edu.pl (K.T.)

3 Regional Centre of Transfusion Medicine, ul. Marii Skłodowskiej-Curie 23, 15-950 Białystok, Poland; azebrowska@rckik.bialystok.pl

4 Department of the Infectious Diseases, Tropical Diseases and Acquired Immunodeficiencies, Pomeranian Medical University, ul. Arkońska 4, 71-455 Szczecin, Poland; mparczewski@yahoo.co.uk

* Correspondence: sambor.grygorczuk@umb.edu.pl

\begin{abstract}
Background: The host factors influencing the susceptibility to and the severity of tick-borne encephalitis (TBE) are poorly defined. The loss-of-function $\triangle 32$ mutation in the chemokine receptor gene CCR5 was identified as a risk factor for West Nile encephalitis and possibly for TBE, suggesting a protective role of CCR5 in Flavivirus encephalitis. Methods: We studied the CCR5 genotype in 205 TBE patients stratified by a clinical presentation and 257 controls from the same endemic area (Podlasie, Poland). The genotype distribution between the groups and differences between TBE patients with different genotypes were analyzed. Results: There were $36(17.6 \%)$ CCR5 $\Delta 32$ heterozygotes and 3 $(1.5 \%)$ homozygotes in the TBE group, with no statistically significant difference in comparison with the controls. The CCR5 $\triangle 32$ allele did not associate with the clinical presentation or the severity of TBE. The cerebrospinal fluid (CSF) inflammatory parameters did not differ between the wild-type $(w t / w t)$ and $w t / \triangle 32$ genotype patients. The TBE clinical presentation and CSF parameters in three $\Delta 32 / \Delta 32$ homozygotes were unremarkable. Conclusions: The lack of association of CCR5 32 with the risk and clinical presentation of TBE challenges the suspected CCR5 protective role. CCR5 is not indispensable for the effective immune response against the TBE virus.
\end{abstract}

Keywords: tick-borne encephalitis; chemokine receptor; CCR5 $\Delta 32$; genetic association study

\section{Introduction}

Tick-borne encephalitis virus (TBEV) is a Flavivirus transmitted by Ixodes ticks and endemic in a large part of the moderate climate zone of Eurasia. The majority of infections with the European TBEV subtype (EuTBEV) remain either asymptomatic [1,2] or too mild to draw medical attention [3] and are recognized only accidentally or by dedicated surveys. The clinically overt cases differ in severity, from uncomplicated meningitis to life-threatening encephalitis or encephalomyelitis $[4,5]$. Factors contributing to a variable outcome of TBEV infections are not well understood, but the individual variability of the host's immune response is considered to play a decisive role [4,6]. Animal models suggest a multi-step process of the disease progression, which may be shaped by the host response at several levels: during the peripheral spread of TBEV, the invasion across the blood-brain barrier (BBB), or the resulting central nervous system (CNS) involvement $[7,8]$. Several polymorphisms in the genes involved in the inflammatory and antiviral response are 
associated with the risk and/or severity of TBE in exposed human populations, constituting potential risk factors and offering an insight into the disease pathogenesis [9-12].

Chemokines are a family of small cytokines that are chemotactic for leukocytes, among other functions involved in attracting different leukocyte populations into an inflammatory focus. The chemokines interact with their specific receptors, which are expressed selectively on different leukocyte populations in a regulated manner. The changeable pattern of the chemokine ligand and receptor expression allows for the differential control of the leukocyte migration and thus may determine the composition of the inflammatory infiltrate and the features of the local immune response $[13,14]$. In CNS infections, it is reflected by a composition of the leukocyte infiltrate in the brain parenchyma and the pleocytosis of the cerebrospinal fluid (CSF), the latter being available for a clinical examination and an important diagnostic criterion [14,15]. In TBE, the CSF cytosis is dominated by Th CD4+ lymphocytes, mostly of the Th1 subset, with the addition of Tc CD8+ cells [16]. The detailed protective and pathogenic effects exerted by these lymphocyte populations were evaluated mainly in post-mortem studies, animal models, and in a few clinical-setting studies, and, to a large extent, remain debatable [17-21].

CCR5 is a receptor for CCL3, CCL4, and CCL5 chemokines, expressed on T lymphocytes in a constitutional and induced manner [14,22]. It is also a human immunodeficiency virus (HIV) co-receptor targeted by a class of antiretroviral drugs, the entry inhibitors, represented by maraviroc [23-25]. In viral encephalitis, it may be involved in a lymphocyte migration into and within the CNS, microglia activation, and an intrathecal inflammatory response, contributing to disease control, but also potentially to an immune-mediated pathology [21,26]. In TBE, the activated intrathecal T CD4+ and T CD8+ lymphocyte populations are enriched in CCR5-positive cells [21]. Mice unable to express CCR5 have unfavorable alterations of the intrathecal response to several Flavivirus species, including the West Nile virus (WNV), the Japanese encephalitis virus, and the Langat virus, closely related to TBEV [27-29]. In humans, this condition may be mimicked in the bearers of the $\triangle 32$ deletion in the CCR5 gene, manifesting itself with a lack of a functional CCR5 in homozygotes and a several-fold reduced expression in heterozygotes [22,24,25]. The CCR5 32 homozygosity correlated with the increased risk of asymptomatic WNV infection and with its fatal outcome in the genetic association studies in North America [30,31], which raised concerns about increased susceptibility to WNV in patients receiving maraviroc $[23,31]$. Consequently, an association of CCR5 32 with the risk of symptomatic TBEV infection has been reported in the Lithuanian population, and a tendency for an association with the clinical severity of asymptomatic TBE was suggested, but not confirmed, in a follow-up study $[9,10]$. Some mechanistic explanations of these associations have been proposed but remain unproven. The protective effect of CCR5 could be exerted during the early peripheral phase of the Flavivirus infection, when it could reduce the risk of a symptomatic disease and neuroinvasion. A decreased CCR5 expression could also decrease Th lymphocyte migration from the periphery into the CNS, hampering the development of the protective intrathecal immune response and increasing the risk and severity of the neurologic involvement [27]. As the CSF of TBE patients contains a large fraction of CCR5-negative T lymphocytes [21,32], other pathways must supplement the chemotactic effect of CCR5 signaling and should be able to compensate for its dysfunction to some degree. Still, the paucity of a functional CCR5 could delay the lymphocyte influx and alter the balance between different intrathecal leukocyte subpopulations, resulting in a less effective and/or more immunopathogenic local response, as observed in some animal models of Flavivirus encephalitis [28,29]. However, the character and extent of these alterations in human TBE remain unknown.

In our previous studies, we were unable to confirm the association between the CCR5 genotype and the risk and severity of TBE, and we have found that CCR5 wt/ $\triangle 32$ heterozygotes were able to mount a normal intrathecal immune response to TBEV [32,33]. Currently, we have attempted to verify these findings in a larger study group and to 
evaluate the clinical presentation of TBE in patients heterozygous and homozygous for CCR5 32 mutation in more detail.

\section{Results}

To assess if the CCR5 genotype influences the risk of symptomatic TBEV infection in exposed individuals, we have first compared the distribution of the genotypes between TBE patients and healthy controls inhabiting the same highly endemic area in Podlasie in the northeast of Poland. There were 39 bearers of the $\Delta 32$ allele in the TBE group (19.1\%), including $36 w t / \Delta 32$ heterozygotes and three $\Delta 32 / \Delta 32$ homozygotes, which did not differ from the frequency in the control group and gave no hint of any association of the CCR5 $\Delta 32$ allele with TBE occurrence (Table 1, top two rows).

Table 1. Distribution of CCR5 genotypes in the study cohort. Frequencies of CCR5 genotypes and the CCR5 allele prevalence in patients with tick-borne encephalitis (TBE) stratified according to clinical variables and in healthy controls from the same area. The frequencies of $w t / w t$ and combined $w t / \Delta 32$ and $\Delta 32 / \Delta 32$ genotypes, as well as $w t$ and $\Delta 32$ allele prevalence, did not differ significantly between the groups.

\begin{tabular}{|c|c|c|c|c|}
\hline \multirow{2}{*}{ Group } & \multicolumn{3}{|c|}{ CCR5 Genotype Prevalence ${ }^{a}$} & \multirow{2}{*}{$\begin{array}{c}\text { CCR5 Allele Prevalence } \\
(w t / \Delta 32 \text { Allele) }\end{array}$} \\
\hline & $w t / w t$ & $w t / \Delta 32$ & $\Delta 32 / \Delta 32$ & \\
\hline Healthy controls $(n=265)$ & $212(82.5 \%)$ & $41(16.0 \%)$ & $4(1.6 \%)$ & $0.905 / 0.095$ \\
\hline $\operatorname{TBE}(n=205)$ & $166(81.0 \%)$ & $36(17.6 \%)$ & $3(1.5 \%)$ & $0.898 / 0.102$ \\
\hline \multicolumn{5}{|l|}{ Clinical presentation } \\
\hline meningitis $(\mathrm{M})(n=109)$ & $88(80.7 \%)$ & $19(17.4 \%)$ & $2(1.8 \%)$ & $0.894 / 0.106$ \\
\hline meningoencephalitis (ME) $(n=77)$ & $63(81.8 \%)$ & $13(16.9 \%)$ & $1(1.3 \%)$ & $0.903 / 0.097$ \\
\hline meningoencephalomyelitis (MEM) $(n=19)$ & $15(78.9 \%)$ & $4(21.1 \%)$ & $0(0.0 \%)$ & $0.895 / 0.105$ \\
\hline \multicolumn{5}{|l|}{ Severity of ME/MEM } \\
\hline mild $(n=43)$ & $36(83.7 \%)$ & $6(14.0 \%)$ & $1(2.3 \%)$ & $0.907 / 0.093$ \\
\hline moderate $(n=36)$ & $30(83.3 \%)$ & $6(16.7 \%)$ & $0(0.0 \%)$ & $0.917 / 0.083$ \\
\hline severe $(n=17)$ & $12(70.6 \%)$ & $5(29.4 \%)$ & $0(0.0 \%)$ & $0.853 / 0.147$ \\
\hline \multicolumn{5}{|l|}{ Consciousness abnormalities } \\
\hline absent $(n=155)$ & $128(82.6 \%)$ & $24(15.4 \%)$ & $3(1.9 \%)$ & $0.903 / 0.097$ \\
\hline present $(n=50)$ : & $38(76.0 \%)$ & $12(24.0 \%)$ & $0(0.0 \%)$ & $0.880 / 0.120$ \\
\hline mild $(n=33)$ & $26(78.8 \%)$ & $7(21.2 \%)$ & $0(0.0 \%)$ & $0.894 / 0.106$ \\
\hline moderate $(n=9)$ & $6(66.7 \%)$ & $3(33.3 \%)$ & $0(0.0 \%)$ & $0.833 / 0.167$ \\
\hline severe $(n=8)$ & $6(75.0 \%)$ & $2(25.0 \%)$ & $0(0.0 \%)$ & $0.875 / 0.125$ \\
\hline \multicolumn{5}{|l|}{ Paresis } \\
\hline absent $(n=187)$ & $152(81.3 \%)$ & $32(17.1 \%)$ & $3(1.6 \%)$ & $0.898 / 0.102$ \\
\hline present $(n=18)$ & $14(77.8 \%)$ & $4(22.2 \%)$ & $0(0.0 \%)$ & $0.889 / 0.111$ \\
\hline \multicolumn{5}{|l|}{ Cerebellar syndrome } \\
\hline absent $(n=166)$ & $134(80.7 \%)$ & $30(18.1 \%)$ & $2(1.2 \%)$ & $0.898 / 0.102$ \\
\hline present $(n=39)$ & $32(82.1 \%)$ & $6(15.4 \%)$ & $1(2.6 \%)$ & $0.897 / 0.103$ \\
\hline \multicolumn{5}{|l|}{ Disease course } \\
\hline monophasic $(n=110)$ & $87(79.1 \%)$ & $21(19.1 \%)$ & $2(1.8 \%)$ & $0.886 / 0.114$ \\
\hline biphasic $(n=92)$ & $78(84.8 \%)$ & $13(14.1 \%)$ & $1(1.1 \%)$ & $0.918 / 0.082$ \\
\hline
\end{tabular}

${ }^{a}$ number of cases (frequency of a genotype in \%); wt-wild type.

Next, we have compared the distribution of the CCR5 genotypes between the subgroups of TBE patients defined by qualitative and semi-quantitative clinical variables. Because there were only three $\Delta 32 / \Delta 32$ homozygotes, in the formal analysis, they were pooled with $w t / \Delta 32$ heterozygotes, and the distributions of the $\Delta 32$-negative and the $\Delta 32$ positive genotypes were compared. The results are presented in Table 1 . The $\Delta 32$ allele did not associate significantly with the clinical presentation (defined as meningitis, meningoencephalitis, or meningoencephalomyelitis), the severity of the neurologic involvement (scored in a simplified four-grade scale from absent to severe), the presence and severity of consciousness abnormalities, and the presence of two frequent neurologic manifestations (paresis and cerebellar syndrome), as well as the history of a clinically distinct peripheral phase. Of note, there were some trends for an association of $\Delta 32$, particularly of the $w t / \Delta 32$ 
genotype, with a more severe TBE (a disease graded as severe, moderate to severe consciousness abnormalities, paresis, and monophasic presentation), but they all depended on small patient numbers and were well below the level of the statistical significance.

There was no significant difference in the basic CSF inflammatory parameters between the TBE patients with $w t / w t$ and $w t / \Delta 32$ genotypes, although the latter tended to have somewhat higher CSF lymphocyte counts (Table 2).

Table 2. The cerebrospinal fluid (CSF) parameters in TBE patients stratified according to CCR5 genotype. The median values of the basic CSF parameters on admission in all TBE patients and in subgroups with CCR5 $w t / w t$ and $w t / \Delta 32$ genotype. There was no significant difference between the compared genotypes.

\begin{tabular}{cccc}
\hline CCR5 Genotype & All & wt/wt & wt/ $\mathbf{\Delta 3 2}$ \\
\hline pleocytosis $^{\mathrm{a}}$ & 92 & 91 & 103 \\
\hline lymphocyte count $^{\mathrm{a}}$ & 58 & 57 & 74 \\
\hline protein $^{\mathrm{b}}$ & 0.65 & 0.66 & 0.63 \\
\hline albumin $^{\mathrm{b}}$ & 0.447 & 0.447 & 0.444 \\
\hline
\end{tabular}

a—cells $/ \mu \mathrm{L} ;{ }^{\mathrm{b}}-\mathrm{g} / \mathrm{L} ; w t$-wild type.

As CCR5 heterozygotes, who constituted the majority of $\triangle 32$-bearing patients, could potentially compensate for the impaired CCR5 expression by the upregulation of the CCL5 and other CCR5 ligands, the normal TBE presentations in them do not exclude the involvement of CCR5 signaling. We have used the opportunity for the detection of three TBE $\Delta 32$ homozygotes, by definition incapable of any functional CCR5 expression, to further constrain its possible pathophysiological role. The main clinical and laboratory findings in these patients are presented in Table 3.

Table 3. The clinical and laboratory characteristics of the individual CCR $5 \Delta 32 / \Delta 32 \mathrm{TBE}$ patients. The selected demographic, clinical, and laboratory parameters in three identified TBE patients with the CCR5 $\Delta 32 / \Delta 32$ genotype.

\begin{tabular}{|c|c|c|c|c|c|c|c|c|c|}
\hline \multirow{2}{*}{ No } & \multirow{2}{*}{ Sex } & \multirow{2}{*}{ Age } & \multirow{2}{*}{ Presentation } & \multirow{2}{*}{$\begin{array}{c}\text { Altered } \\
\text { Consciousness }\end{array}$} & \multirow{2}{*}{$\begin{array}{l}\text { Neurological } \\
\text { Symptoms }\end{array}$} & \multicolumn{4}{|c|}{ CSF Parameters on Admission } \\
\hline & & & & & & Pleocytosis $^{a}$ & Lymphocytes a & Protein $^{b}$ & Albumin ${ }^{b}$ \\
\hline 1 & $\mathrm{~m}$ & 34 & M & no & no & 58 & NA & 0.35 & 0.239 \\
\hline 2 & $\mathrm{~m}$ & 46 & M & no & no & 63 & 45 & 1.12 & 0.787 \\
\hline 3 & $\mathrm{f}$ & 38 & $\mathrm{ME}$ & no & $\begin{array}{l}\text { cerebellar } \\
\text { syndrome }\end{array}$ & 193 & 58 & 0.76 & 0.508 \\
\hline
\end{tabular}

a—cells $/ \mu \mathrm{L} ;{ }^{\mathrm{b}}$-g/L; m—male; $\mathrm{f}$-female; $\mathrm{M}$-meningitis; ME—meningoencephalitis; NA—non-available.

In general, the clinical TBE presentation in CCR5 $\Delta 32 / \Delta 32$ patients was unremarkable and relatively mild. None of them had severe disease, and two presented with meningitis with no neurologic complications. Their CSF parameters were also within the range of the values found in $w t / w t$ homozygotes and individually variable, without any consistent trend common to all of them.

\section{Discussion}

Our results do not exclude the possibility of CCR5 being expressed and participating in the immune response in human TBE, as suggested by different lines of evidence revealed in previous studies $[9,10,29,32]$. However, they strongly suggest that (1) CCR5 is not essential in preventing symptomatic disease and CNS involvement in TBEV-exposed individuals, which means it probably does not play a decisive role in the primary infection focus or during the viremic phase; (2) it is not indispensable in controlling CNS infection by TBEV. 
Our results differ from the previous findings of Kindberg et al. and Mickiene et al. Kindberg et al. compared 129 TBE patients from Lithuania with 134 healthy controls and groups of historical population controls from Lithuania and Sweden, finding a significantly higher $C C R 5 \Delta 32$ allele frequency in the TBE group. The study identified three CCR5 $\Delta 32 / \Delta 32$ homozygotes $(2.3 \%)$ in the TBE cohort and none among TBEV-naive controls and found a trend for a higher frequency of $w t / \Delta 32$ genotype in TBE than in controls $(22.5 \%$ and $16.4 \%$, respectively). There was also a tendency for an association of the $\Delta 32$ allele with a more severe TBE presentation [9]. The study by Mickienè et al. compared three cohorts of pediatric and adult TBE patients (349 TBE cases) with 135 healthy subjects. It corroborated the association of CCR5 $\triangle 32$ with the risk of TBE but was unable to replicate the association with clinical severity [10]. Both studies included groups of patients with aseptic non-TBE meningitis/meningoencephalitis who presented with the CCR5 32 frequency that was not different from healthy controls and lower than in TBE patients. The results were suggestive of a specific role of CCR5 in TBE and not in other viral CNS infections [9,10]. In our previous study including patients and controls from the northeast area of Poland, we were unable to replicate these findings, but our study group was relatively small (59 TBE patients and 57 controls) [33]. Currently, however, we have obtained similar negative results with a much larger study population. The variability of TBEV strains and/or genetic background in study populations could possibly contribute to the difference between our current results and those of Kindberg et al. and Mickiene et al. despite the studies being conducted in adjacent geographic areas. Interestingly, similarly to us, Barkash et al. did not detect an association of the CCR5 genotype with the susceptibility to TBE in the Russian population in the area dominated by the Siberian TBEV subtype [34]. However, both in Lithuania and in northeast Poland, only the European (Western) TBEV subtype has been detected, which additionally shows relatively little variation between the strains isolated in different European sites [35-37]. All of this makes the intra-strain virus variability an unlikely explanation of the difference between the results obtained in the adjacent areas of Lithuania and Poland. As the discussed effects of the CCR5 genotype on the TBE rate and presentation are rather subtle, the discrepancy can be overcome by further studies with a higher statistical power.

As we were able to document a normal clinical presentation and CSF cellular parameters in the $\Delta 32 / \Delta 32$ homozygotes, we can be confident that CCR5 is not indispensable for a normal inflammatory response and lymphocyte migration into the CSF in TBE. This should reduce the concerns about the security of anti-CCR5 therapies in persons exposed to TBEV. Based on our current data, we cannot exclude a weak trend for a more severe presentation of TBE and, somewhat counterintuitively, higher lymphocytic pleocytosis in the $w t / \Delta 32$ heterozygotes. Such a tendency would be consistent with the findings of Kindberg et al. [9] and could be attributed to changes in the activity of other immune mediators in the face of a reduced CCR5 expression, as suggested by animal studies [28,29]. However, before any further interpretation attempts are made, the tentative trend needs to be verified in further studies.

In conclusion, we suggest that either the CCR5 axis is not essential in the response to TBEV in humans, and its reduced expression does not influence the course of the infection, or, more likely, it is engaged in that response, but not indispensable, and can be effectively replaced by other signaling routes. In the second case, some possibly unfavorable alterations of the immune response to the TBEV may be expected in persons with a hampered CCR5 expression, but any potential clinical effects would be limited and must be confirmed by follow-up research.

\section{Materials and Methods}

The study group consisted of 205 TBE patients hospitalized from 2016 to 2020 in the Department of the Infectious Diseases and Neuroinfections and the Department of the Pediatric Infectious Diseases of the Medical University in Białystok (Podlasie, Poland). All patients had an epidemiologic and clinical history consistent with the diagnosis of TBE, cor- 
roborated by either the detection of specific anti-TBEV IgM and/or IgG antibodies in serum and/or CSF on admission or by seroconversion, fulfilling the criteria of a confirmed TBE case [38]. The serologic testing was performed with FSME/TBE Elisa IgM and FSME/TBE Elisa IgG from VIROTECH Diagnostics GmbH (Germany). There were 134 males (65.4\%) and 74 females (34.6\%), from 6 to 88 years old (mean 45.7 years), including 12 pediatric patients (6-17 years old) and 193 adults. Three patients did not undergo lumbar puncture because of contraindications, and five had a borderline CSF cytosis (8-14 cells $/ \mu \mathrm{L})$; all the others $(198 ; 96 \%)$ had a confirmed pleocytosis $>15$ cells $/ \mu \mathrm{L}$. All but two patients $(203 ; 99 \%)$ were IgM-positive towards TBEV either in serum or CSF and most of them both in serum and CSF simultaneously. The patients were not screened for a potential cross-reactivity with related viruses, but as there are no known Flavivirus species other than the TBEV circulation in the study area, we consider the probability of such infections to be extremely small. Most patients denied any previous anti-TBEV vaccination, but 2 (1.0\%) reported having undergone an incomplete vaccination scheme-they were not excluded, as their both clinical and serologic presentation was consistent with a current infection with TBEV. The patients were stratified according to the clinical severity and main neurologic symptoms. Patients with meningeal syndrome but no focal neurologic deficits or altered consciousness were classified as having uncomplicated meningitis (M), whereas patients with an altered mental status and/or any focal CNS involvement were classified as having meningoencephalitis (ME) or meningoencephalomyelitis (MEM). The CNS abnormalities were graded as absent (corresponding to $\mathrm{M}$ ); mild (paresthesia, pathologic reflexes, nystagmus, mild gait disorders); moderate (focal symptoms including paresis and/or lethargy); and severe (multiple or severe focal deficits, disorientation, loss of consciousness). Consciousness abnormalities were stratified as mild (lethargy) through moderate (agitation or disorientation) to severe (loss of consciousness), paresis, and cerebellar syndrome-as present or absent. The patients were also stratified as having either a classical biphasic course of TBE with a distinct peripheral phase before the onset of meningitis or a more rapidly progressive, monophasic presentation. The CSF inflammatory parameters (pleocytosis with leukocyte differential, protein, and albumin concentration) were evaluated by standard laboratory techniques in a hospital diagnostic laboratory.

The control group was recruited from a population of 300 healthy adult blood donors applying to the Regional Centre of Transfusion Medicine in Białystok, within the study area. Each blood donor was asked to fill out a short questionnaire asking about 1) a history of a diagnosed tick-borne encephalitis, or 2) a history of vaccination against TBE, and the participants reporting either of these were excluded, leaving a group of 257 controls, including 192 males (74.7\%) and 65 females (25.3\%), ranging from 18 to 63 years old (mean age of 34.8 years).

Because both the control and patient groups were recruited in the same geographic area and were ethnically uniform, we did not undertake further demographic stratification. The patients and controls gave written, informed consent for inclusion. The study was approved by the Ethics Committee of the Medical University in Białystok (approval no R-I-002/308/2019).

A sample of $1 \mathrm{~mL}$ of venous blood was obtained in an EDTA-coated tube during the hospital stay in patients and directly before a blood donation in controls, kept in $4-5{ }^{\circ} \mathrm{C}$ for no more than $72 \mathrm{~h}$, frozen to $-20^{\circ} \mathrm{C}$, and stored till DNA extraction. QIAamp DNA Blood Mini Kit (QIAgen, Hilden, Germany) was used to extract genomic DNA, following the manufacturer's protocol. DNA was re-suspended in $200 \mu \mathrm{L}$ of AE buffer (QIAgen, Hilden, Germany) and stored at $4{ }^{\circ} \mathrm{C}$ for further analyses. The genotyping was performed in the laboratory of the Department of Infectious Diseases, Tropical Diseases, and Acquired Immunodeficiencies of Pomeranian Medical University in Szczecin. To analyze CCR5 32 variation, PCR with sequence-specific primers was used as described previously [39]. Visualization under UV light was performed after electrophoresis on the $2.5 \%$ agarose gel (SIGMA, Saint Louis, MO, USA) stained with DNA-star dye (Lonza Inc., Rockland, ME, 
USA). Genotyping was successful in all 465 samples. No deviation from Hardy-Weinberg equilibrium WHE was detected.

We have used Pearson's chi-square test to compare the wt and $\Delta 32$ allele frequency in TBE patients and controls, as well as in the TBE patient subgroups defined by clinical presentation. We have compared basic CSF parameters (pleocytosis, lymphocyte count, neutrophil count, protein, and albumin concentration) between the patients with $w t / w t$ and $w t / \Delta 32$ genotypes with the U Mann-Whitney test. $p<0.05$ was considered significant. The analysis was separately performed with the exclusion of 8 patients with no confirmed pleocytosis, one of whom had $w t / \Delta 32$ and $7 w t / w t$ genotype, with a marginal influence on the results and no change to their statistical interpretation.

Author Contributions: Conceptualization, S.G.; Methodology, S.G., J.D.-M. and M.P. Validation, S.G., A.S., M.P.; Formal Analysis, S.G. and M.P.; Investigation, A.S., K.T., J.D.-M., A.Ż., and P.C.; Resources, K.T., A.Ż. and P.C.; Data Curation, J.D.-M., S.G. and M.P.; Writing-Original Draft Preparation, S.G.; Writing—Review and Editing, S.G., J.D.-M., A.S., M.P.; Visualization, S.G.; Supervision, S.G. and M.P.; Project Administration, S.G. and M.P.; Funding Acquisition, S.G. All authors have read and agreed to the published version of the manuscript.

Funding: The study has been funded by the National Science Centre (Narodowe Centrum Nauki, NCN), Poland, grant no 2018/31/B/NZ6/02744.

Institutional Review Board Statement: The study was approved by the Ethics Committee of the Medical University in Białystok (approval no R-I-002/308/2019).

Informed Consent Statement: Informed consent was obtained from all subjects involved in the study.

Data Availability Statement: The data presented in this study are available on request from the corresponding author.

Conflicts of Interest: The authors declare no conflict of interest. The funders had no role in the design of the study; in the collection, analyses, or interpretation of data; in the writing of the manuscript; or in the decision to publish the results.

\section{References}

1. Hansson, M.E.A.; Örvell, C.; Engman, M.-L.; Wide, K.; Lindquist, L.; Lidefelt, K.-J.; Sundin, M. Tick-borne encephalitis in childhood. Rare or missed? Pediatr. Infect. Dis. J. 2011, 30, 355-357. [CrossRef]

2. Gustafson, R.; Svenungsson, B.; Fosgren, M.; Gardulf, A.; Granstrom, M. Two-year survey of the incidence of Lyme borreliosis and tick-borne encephalitis in a high-risk population in Sweden. Eur. J. Clin. Microbiol. Infect. Dis. 1992, 11, 894-900. [CrossRef]

3. Lotrič-Furlan, S.; Avsič-Županc, T.; Strle, F. An abortive form of tick-borne encephalitis (TBE)-A rare clinical manifestation of infection with TBE virus. Wien. Klin. Wochenschr. 2002, 114, 627-629.

4. Bogovič, P.; Strle, P. Tick-borne encephalitis: A review of epidemiology, clinical characteristics and management. World J. Clin. Cases 2015, 3, 430-441. [CrossRef]

5. Radzišauskienè, D.; Žagminas, K.; Ašoklienè, L.; Jasionis, A.; Mameniškienė, R.; Ambrozaitis, A.; Jančorienè, L.; Jatužis, D.; Petraitytė, I.; Mockienè, E. Epidemiological patterns of tick-borne encephalitis in Lithuania and clinical features in adults in the light of the high incidence in recent years: A retrospective study. Eur. J. Neurol. 2018, 25, 268-274. [CrossRef]

6. Saksida, A.; Jakopin, N.; Jelovšek, M.; Knap, N.; Fajs, L.; Lusa, L.; Lotrič-Furlan, S.; Bogovič, P.; Arnež, M.; Strle, F.; et al. Virus RNA Load in Patients with Tick-Borne Encephalitis, Slovenia. Emerg. Infect. Dis. 2018, 24, 1315-1323. [CrossRef]

7. Hayasaka, D.; Nagata, N.; Fujii, Y.; Hasegawa, H.; Sata, T.; Suzuki, R.; Gould, E.A.; Takashima, I.; Koike, S. Mortality following peripheral infection with Tick-borne encephalitis virus results from a combination of central nervous system pathology, systemic inflammatory and stress responses. Virology 2009, 390, 139-150. [CrossRef]

8. Palus, M.; Vojtî̌šková, J.; Salát, J.; Kopecký, J.; Grubhoffer, L.; Lipoldová, M.; Demant, P.; Růžek, D. Mice with different susceptibility to tick-borne encephalitis virus infection show selective neutralizing antibody response and inflammatory reaction in the central nervous system. J. Neuroinflamm. 2013, 10, 77-89. [CrossRef]

9. Kindberg, E.; Mickiené, A.; Ax, C.; Åkerlind, B.; Vene, S.; Lindquist, L.; Lundkvist, A.; Svennsonn, L. A deletion in the chemokine receptor 5 (CCR5) gene is associated with tickborne encephalitis. J. Infect. Dis. 2008, 197, 266-269. [CrossRef]

10. Mickienè, A.; Pakalniene, J.; Nordgren, J.; Carlsson, B.; Hagbom, M.; Svensson, L.; Lindquist, L. Polymorphisms in Chemokine Receptor 5 and Toll-Like Receptor 3 Genes Are Risk Factors for Clinical Tick-Borne Encephalitis in the Lithuanian Population. PLoS ONE 2014, 9, e106798. [CrossRef] 
11. Barkhash, A.V.; Perelygin, A.A.; Babenko, V.N.; Myasnikova, N.G.; Pilipenko, P.I.; Romaschenko, A.G.; Voevoda, M.I.; Brinton, M.A. Variability in the $2^{\prime}-5^{\prime}$-oligoadenylate synthetase gene cluster is associated with human predisposition to tick-borne encephalitis virus-induced disease. J. Infect. Dis. 2010, 202, 1813-1818. [CrossRef]

12. Barkhash, A.V.; Perelygin, A.A.; Babenko, V.N.; Brinton, M.A.; Voevoda, M.I. Single nucleotide polymorphism in the promoter region of the CD209 gene is associated with human predisposition to severe forms of tick-borne encephalitis. Antivir. Res. 2012, 93, 64-68. [CrossRef]

13. Bachelerie, F.; Ben-Baruch, A.S.; Burkhardt, A.M.; Combadiere, C.; Farber, J.M.; Graham, G.J.; Horuk, R.; Sparre-Ulrich, A.H.; Locati, M.; Luster, A.D.; et al. International Union of Basic and Clinical Pharmacology. LXXXIX. Update on the Extended Family of Chemokine Receptors and Introducing a New Nomenclature for Atypical Chemokine Receptors. Pharmacol. Rev. 2014, 66, 1-79. [CrossRef]

14. Bardina, S.V.; Lim, J.K. The role of chemokines in the pathogenesis of neurotropic flaviviruses. Immunol. Res. 2012, 54, 121-132. [CrossRef]

15. Venkatesan, A.; Tunkel, A.R.; Bloch, K.C.; Lauring, A.S.; Sejvar, J.; Bitnun, A.; Stahl, J.-P.; Mailles, A.; Drebot, M.; Rupprecht, C.E.; et al. Case Definitions, Diagnostic Algorithms, and Priorities in Encephalitis: Consensus Statement of the International Encephalitis Consortium. Clin. Infect. Dis. 2013, 57, 1114-1128. [CrossRef]

16. Lepej, S.Ž.; Mišić-Majerus, L.; Jeren, T.; Rode, O.D.; Remenar, A.; Šporec, V.; Vince, A. Chemokines CXCL10 and CXCL11 in the cerebrospinal fluid of patients with tick-borne encephalitis. Acta. Neurol. Scand. 2007, 115, 109-114. [CrossRef]

17. Gelpi, E.; Preusser, M.; Laggner, U.; Garzuly, F.; Holzmann, H.; Heinz, F.X.; Budka, H. Inflammatory response in human tick-borne encephalitis: Analysis of postmortem brain tissue. J. NeuroVirol. 2006, 12, 322-327. [CrossRef]

18. Maximova, O.A.; Faucette, L.J.; Ward, J.M.; Murphy, B.R.; Pletnev, A.G. Cellular Inflammatory Response to Flaviviruses in the Central Nervous System of a Primate Host. J. Histochem. Cytochem. 2009, 57, 973-989. [CrossRef]

19. Růžek, D.; Salát, J.; Singh, S.K.; Kopecký, J. Breakdown of the Blood-Brain Barrier during Tick-Borne Encephalitis in Mice Is Not Dependent on CD8+ T-Cells. PLoS ONE 2011, 6, e20472. [CrossRef]

20. Palus, M.; Formanová, P.; Salát, J.; Žampachová, E.; Elsterová, J.; Růžek, D. Analysis of serum levels of cytokines, chemokines, growth factors, and monoamine neurotransmitters in patients with tick-borne encephalitis: Identification of novel inflammatory markers with implications for pathogenesis. J. Med. Virol. 2015, 87, 885-892. [CrossRef]

21. Grygorczuk, S.; Osada, J.; Toczyłowski, K.; Sulik, A.; Czupryna, P.; Moniuszko-Malinowska, A.; Kondrusik, M.; Świerzbińska, R.; Dunaj, J.; Pancewicz, S.; et al. The lymphocyte populations and their migration into the central nervous system in tick-borne encephalitis. Ticks Tick-Borne Dis. 2020, 11, 101476. [CrossRef]

22. Patterson, B.K.; Czerniewski, M.A.; Andersson, J.; Sullivan, Y.; Su, F.; Jiyamapa, D.; Burki, Z.; Landay, A. Regulation of CCR5 and CXCR4 expression by type 1 and type 2 cytokines: CCR 5 expression is downregulated by IL-10 in CD4-positive lymphocytes. Clin. Immunol. 1999, 91, 254-262. [CrossRef]

23. Gulick, R.M.; Lalezari, J.; Goodrich, J.; Clumeck, N.; DeJesus, E.; Horban, A.; Nadler, J.; Clotet, B.; Karlsson, A.; Wohlfeiler, M.; et al. Maraviroc for Previously Treated Patients with R5 HIV-1 Infection. N. Engl. J. Med. 2008, 359, 1429-1441. [CrossRef]

24. Lucotte, G. Frequencies of 32 base pair deletion of the $(\Delta 32)$ allele of the CCR5 HIV-1 co-receptor gene in Caucasians: A comparative analysis. Infect. Genet. Evol. 2002, 1, 201-205. [CrossRef]

25. Wu, L.; Paxton, W.A.; Kassam, N.; Ruffing, N.; Rottman, J.B.; Sullivan, N.; Choe, H.; Sodroski, J.; Newman, W.; Koup, R.A.; et al. CCR5 Levels and Expression Pattern Correlate with Infectability by Macrophage-tropic HIV-1, In Vitro. J. Exp. Med. 1997, 185, 1681-1692. [CrossRef]

26. Sorce, S.; Myburgh, R.; Krause, K.-H. The chemokine receptor CCR5 in the central nervous system. Prog. Neurobiol. 2011, 93, 297-311. [CrossRef]

27. Glass, W.G.; Lim, J.K.; Cholera, R.; Pletnev, A.G.; Gao, J.-L.; Murphy, P.M. Chemokine receptor CCR5 promotes leukocyte trafficking to the brain and survival in West Nile virus infection. J. Exp. Med. 2005, 202, 1087-1098. [CrossRef]

28. Larena, M.; Regner, M.; Lobigs, M. The Chemokine Receptor CCR5, a Therapeutic Target for HIV/AIDS Antagonists, Is Critical for Recovery in a Mouse Model of Japanese Encephalitis. PLoS ONE 2012, 7, e44834. [CrossRef]

29. Michlmayr, D.; Bardina, S.V.; Rdriguez, C.A.; Pletnev, A.G.; Lim, J.K. Dual function of Ccr5 during Langat virus encephalitisreduction of neutrophil-mediated CNS inflammation and increase in T cell-mediated viral clearance. J. Immunol. 2016, 196, 4622-4631. [CrossRef]

30. Glass, W.G.; McDermott, D.H.; Lim, J.K.; Lim, J.K.; Lekhong, S.; Yu, S.F.; Frank, W.A.; Pape, J.; Cheshier, R.C.; Murphy, P.M. CCR5 defi-ciency increases risk of symptomatic West Nile virus infection. J. Exp. Med. 2006, 203, 35-40. [CrossRef]

31. Lim, J.K.; McDermott, D.H.; Lisco, A.; Foster, G.A.; Krysztof, D.; Follmann, D.; Stramer, S.L.; Murphy, P.M. CCR5 Deficiency Is a Risk Factor for Early Clinical Manifestations of West Nile Virus Infection but not for Viral Transmission. J. Infect. Dis. 2010, 201, 178-185. [CrossRef] [PubMed]

32. Grygorczuk, S.; Osada, J.; Parczewski, M.; Moniuszko, A.; Swierzbinska, R.; Kondrusik, M.; Czupryna, P.; Dunaj, J.; Dabrowska, M.; Pancewicz, S. The expression of the chemokine receptor CCR5 in tick-borne encephalitis. J. Neuroinflamm. 2016, 13, 45. [CrossRef]

33. Czupryna, P.; Parczewski, M.; Grygorczuk, S.; Pancewicz, S.; Zajkowska, J.; Dunaj, J.; Kondrusik, M.; Krawczuk, K.; MoniuszkoMalinowska, A. Analysis of the relationship between single nucleotide polymorphism of the CD209, IL-10, IL-28 and CCR5 
$\Delta 32$ genes with the human predisposition to developing tick-borne encephalitis. Postępy Hig. Med. Doświadczalnej 2017, 71, 788-796.

34. Barkhash, A.V.; Voevoda, M.I.; Romaschenko, A.G. Association of single nucleotide polymorphism rs3775291 in the coding region of the TLR3 gene with predisposition to tick-borne encephalitis in a Russian population. Antivir. Res. 2013, 99, 136-138. [CrossRef]

35. Mickiene, A.; Vene, S.; Golovljova, I.; Laiskonis, A.; Lindquist, L.; Plyusnin, A.; Lundkvist, A. Tick-borne Encephalitis Virus in Lithuania. Eur. J. Clin. Microbiol. Infect. Dis. 2001, 20, 886-888. [CrossRef]

36. Kondrusik, M.; Golovljova, I.; Zajkowska, J.M.; Pancewicz, S.; Grygorczuk, S.; Moniuszko, A.; Czupryna, P. Genetic characterisation and prevalence of TBE virus obtained from Ixodes ricinus ticks from North Eastern Poland. In Proceedings of the 12th International Conference on Lyme Borreliosis and Other Tick-Borne Diseases, Ljubljana, Slovenia, 26-29 September 2010.

37. Demina, T.V.; Tkachev, S.E.; Kozlova, I.V.; Doroshchenko, E.K.; Lisak, O.V.; Suntsova, O.V.; Verkhozina, M.M.; Dzhioev, Y.P.; Paramonov, A.I.; Tikunov, A.Y.; et al. Comparative analysis of complete genome sequences of European subtype tick-borne encephalitis virus strains isolated from Ixodes persulcatus ticks, long-tailed squirrel (Spermophilus undulatus), and human blood in the Asian part of Russia. TTBD 2017, 8, 547-553. [CrossRef]

38. European Commission. Commission Implementing Decision (EU) 2018/945 of 22 June 2018 on the Communicable Diseases and Related Special Health Issues to be Covered by Epidemiological Surveillance as Well as Relevant Case Definitions. 2018. Available online: https:/ / eur-lex.europa.eu/legal-content/en/TXT/?uri=CELEX\%3A32018D0945 (accessed on 25 December 2021).

39. Kristiansen, T.B.; Knudsen, T.B.; Ohlendorff, S.; Eugen-Olsen, J. A new multiplex PCR strategy for the simultaneous de-termination of four genetic polymorphisms affecting HIV-1 disease progression. J. Immunol. Methods 2001, 252, 147-151. [CrossRef] 